\title{
REVIEWS IN PAIN
}

\section{A BPS publication}

VOL. I - NO. 2 - MARCH 2008

A t first sight the three articles here, the review of opioids, the review of non-obstetric pain in pregnancy and the review of cultural influences in pain have little in common, except perhaps that common is the linking attribute. Pregnancy is common, and the maternity department here has multiple posters about back pain and symphysis pubis pain. We use opioids widely in acute, obstetric and chronic pains, and in all three contexts we have to manage patients from a multiplicity of different ethnic backgrounds for whom English may not be their preferred language for medical consultations.

The issue of whether or not epidurals in labour increased the chance of later having back pain is a good example of the problems we face when trying to prove a negative. It took a long time for the issue to be resolved, and it is good to see the firm statement here. I detect the thread of similar problems when trying to show that opioid analgesia in labour does not damage the baby in perpetuity.

I think taking pain histories across languages is fraught, in chronic pain at least. The authors here talk about differences in beliefs, and these differences, sometimes with religious overtones, trip us all up sooner or later. Opioid prescription as an example may be unacceptable, perhaps forcing the use of interventions that I regard as considerably less suitable. Sons or daughters translating for parents worries me, particularly when a long reply is then translated in just a few words. Tricky.

The opioid receptor story has been around for most of my clinical career, and it is fun to see the bits which have survived and the bits which have fallen by the wayside (e.g. the sigma receptor). Much remains to be done - just what are the endogenous opioids doing to each of us normally, and why does naloxone not tell us? Or maybe that's too simple.

\section{Henry McQuay}

Nuffield Professor of Clinical Anaesthetics, University of Oxford

C O N T E N T S

Basic opioid pharmacology

J. Williams - Page 2

Cultural issues in pain

S.M. Peacock \& S. Patel - Page 6

Non-obstetric pain in pregnancy

A. Lalkhen \& K. Grady - Page 10

EDITORIAL BOARD

Professor Jon Raphael Editor-in-chief

Birmingham, Pain Medicine

Professor Sam H Ahmedzai Sheffeld, Palliative Medicine

Dr Eloise Carr

Bournemouth, Nursing

Dr Kate Grady Manchester Anaesthesia and Pain Medicine

Dr Lorimer Moseley Oxford, Physiotherapy

Professor Richard Langford London

Pharmacology and Acute Pain

Ms Ann Taylor

Cardiff, Nursing

Dr Miles Thompson Bath, Psychology

Professor Irene Tracey Oxford, Physiology

PRODUCTION TEAM

Ruth Day

Rikke Warming

Yves Lebrec 